\title{
Synthesis and Characterization of $\mathrm{Hybrid} \mathrm{Ni}_{0.5} \mathrm{Zn}_{0.5} \mathrm{Fe}_{2} \mathrm{O}_{4} @ \mathrm{SiO}_{2} /$ chitosan
}

\author{
Polyana Tarciana Araújo dos Santos *, Patrícia Tatiana Araújo dos Santos ${ }^{a}$, Pascally Maria
}

Aparecida Guerra de Araújo ${ }^{a}$, Daniel Reinaldo Cornejo ${ }^{b}$, Ana Cristina Figueiredo de Melo Costa ${ }^{a}$

\author{
${ }^{a}$ Department of Materials Engineering, Federal University of Campina Grande, \\ Campina Grande, PB, Brazil. \\ ${ }^{b}$ Department of Physics of Materials and Mechanics, Institute of Physics, University of São Paulo, \\ São Paulo, SP, Brazil.
}

Received: March 23, 2017; Revised: May 31, 2017; Accepted: July 26, 2017

\begin{abstract}
In this work we evaluate the use of silane agent 3-aminopropyltrimethoxysilane and biopolymer chitosan to functionalize ferrites $\mathrm{Ni}_{0.5} \mathrm{Zn}_{0.5} \mathrm{Fe}_{2} \mathrm{O}_{4}$ using the solvent evaporation method aiming at obtaining hybrid material $\mathrm{Ni}_{0.5} \mathrm{Zn}_{0.5} \mathrm{Fe}_{2} \mathrm{O}_{4} @ \mathrm{SiO}_{2} /$ chitosan for use as a biosensor. The nanoparticles before and after the functionalization showed the major phase $\mathrm{Ni}_{0.5} \mathrm{Zn}_{0.5} \mathrm{Fe}_{2} \mathrm{O}_{4}$. The FTIR spectra showed absorption bands characteristic of $\mathrm{CO}$, axial deformation of $\mathrm{CN}$ and $\mathrm{SiO}$ band from the silane agent which proved functionalization. The functionalization of ferrite $\mathrm{Ni}_{0.5} \mathrm{Zn}_{0.5} \mathrm{Fe}_{2} \mathrm{O}_{4}$ with chitosan caused a $36.36 \%$ reduction in saturation magnetization as compared with ferrite synthesized, however it maintained the ferrimagnetic characteristic indicating to be a promising material for the use in biotechnological applications as for example in magnetic biosensors.
\end{abstract}

Keywords: biopolymer, magnetic nanoparticles, chitosan.

\section{Introduction}

Hybrid materials (HM) combine the advantages of organic polymers (e.g., photoluminescence, flexibility, easy processing) with those of inorganic compounds, such as thermal and chemical stability ${ }^{1}$. Many approaches have been reported recently about the preparation of hybrid compounds, such as enzyme immobilization ${ }^{2}$, drug carriers, optical imaging ${ }^{3}$, gene therapy ${ }^{4}$ and electrochemical sensors ${ }^{5}$.

Of the important applications of magnetic nanoparticles in nanotechnology can be mentioned diagnosis and treatment of cancer, immobilization and isolation of biomolecules and various enzymes, targeted drug delivery, diagnostic agents magnetically guided, biosensor, hyperthermia ${ }^{6-11}$.

Biosensors comprise a number of different components amongwhich the most important part constitutes magnetic particles ${ }^{12}$. The implication of magnetic particles in biosensors means that it is important to have a better understanding of the properties of magnetic particles. Recently, great attention has been devoted to syntheses of various magnetic nanoparticles due to their widespread applications in many fields such as biomedicine, biotechnology, materials science and environmental areas ${ }^{13,14}$.

The Ni-Zn ferrites are one of the most versatile magnetic materials for magnetic biosensor development, since it presents saturation magnetization and high Curie temperature, chemical stability as well as low coercivity ${ }^{15}$ and in the case of systems formed by nanoparticles may exhibit superparamagnetism ${ }^{16}$, which is the most promising magnetic behavior for biomedical applications. Furthermore, for use in biological and medical fields, they must be monodisperse magnetic nanoparticles and bind to biomolecules ${ }^{15}$.

$\mathrm{Ni}-\mathrm{Zn}$ ferrites have been used with different polymer matrices producing hybrid materials. For a better compatibility between the inorganic oxide and the polymer it is necessary to pre-treat the ferrite through the ion exchange or the chemical modification of the surface of the particles ${ }^{15}$.

In this process of chemical modification of the inorganic nanoparticles either by silane agents or biocompatible polymers or even by the combination of both makes possible these materials, the reduction of toxicity, biological compatibility and antimicrobial activity ${ }^{16,17}$ and also with the purpose of avoiding aggregation, sedimentation of the particles, as well as grant bridges of biological conjunction.

Polymer-coated magnetic nanoparticles have aroused great interest and application in the fields of biotechnology and medicine in recent years, since they can be separated and collected from the medium with the application of a magnetic field ${ }^{18}$.

Among the various polymers used for the immobilization of biomolecules and biosensor applications, chitosan, has unique properties of biopolymers, particularly due to the presence of primary amino groups ${ }^{19}$, reactive groups distributed in a polymer matrix, which allows biological conjugation. 
Chitosan is a biopolymer interesting for this purpose due to their excellent film-forming ability, high permeability, mechanical strength, non-toxicity, biocompatibility, low cost and good availability ${ }^{20}$. Chitosan is a product with a high deacetylated molar mass of chitin, the second most abundant polysaccharide in nature, has structural characteristics similar to glycosaminoglycans and has numerous interesting biological properties ${ }^{21}$.

In this context, the aim of this study was to obtain the hybrid $\mathrm{Ni}_{0.5} \mathrm{Zn}_{0.5} \mathrm{Fe}_{2} \mathrm{O}_{4} @ \mathrm{SiO}_{2} /$ chitosan, from the functionalization of $\mathrm{Ni}$-Zn ferrite with silane agent 3-aminopropyltrimethoxysilane and biopolymer chitosan aiming its use in biomedicine as magnetic biosensor. To this end, an investigation of the structure, morphology, thermal and magnetic properties was conducted.

\section{Material and Methods}

For the synthesis of NPMs all the precursors used for this synthesis were high purity chemicals obtained from VETEC, the following reagents were used: Urea - CO $\left(\mathrm{NH}_{2}\right)_{2}$; iron nitrate nonohydrate - $\mathrm{Fe}\left(\mathrm{NO}_{3}\right)_{3}{ }_{3} 9 \mathrm{H}_{2} \mathrm{O}$; zinc nitrate hexahydrate $-\mathrm{Zn}\left(\mathrm{NO}_{3}\right)_{2} \cdot 6 \mathrm{H}_{2} \mathrm{O}$; nickel nitrate hexahydrate - $\mathrm{Ni}$ $\left(\mathrm{NO}_{3}\right)_{2} \cdot 6 \mathrm{H}_{2} \mathrm{O}$; Cobalt nitrate II trihydrate - $\mathrm{Co}\left(\mathrm{NO}_{3}\right)_{2} \cdot 3 \mathrm{H}_{2} \mathrm{O}$.

The solutions containing the oxidizing reagents and source of metal cations and the urea (reducing agent) were obtained from the total valence of the oxidizing and reducing reagents using the theory of propellants and explosives proposed by Jain et al.(1981 $)^{22}$, in order to favor the stoichiometric oxidant/fuel ratio, $\Phi_{\mathrm{e}}=1$.

The redox mixture of the oxidizing and reducing reagents prepared according to the preset stoichiometry was obtained in a vessel with a capacity of $20 \mathrm{~g}$ batch and submitted to direct heating in a conical reactor with electrical resistance (temperature approximately $600{ }^{\circ} \mathrm{C}$ ) ${ }^{23}$ Until it reaches the auto-ignition (combustion). Then the reaction product (porous flakes) was de-agglomerated in 325 (mesh ABNT $45 \mu \mathrm{m}$ ) and submitted to the characterizations. The sample of ferrite $\mathrm{Ni}-\mathrm{Zn}\left(\mathrm{Ni}_{0.5} \mathrm{Zn}_{0.5} \mathrm{Fe}_{2} \mathrm{O}_{4}\right)$ as synthesized was designated of $\mathrm{NZ}$ and were submitted for characterizations.

For the signaling process all the precursors used for this synthesis were high purity chemicals obtained from SIGMA ALDRICH, The following reagents were used: 3-aminopropyltrimethoxysilane - APTS - $\left[\mathrm{H}_{2} \mathrm{~N}\left(\mathrm{CH}_{2}\right)_{3} \mathrm{Si}\left(\mathrm{OCH}_{3}\right)_{3}\right]$; Toluene - $\mathrm{C}_{7} \mathrm{H}_{8}$; Ethyl alcohol - $\mathrm{C}_{2} \mathrm{H}_{6} \mathrm{O}$.

For the modification of the surface of the NPMs under study were placed $5 \mathrm{~g}$ of the NPMs previously oven dried at $100^{\circ} \mathrm{C}$ with $5 \mathrm{~mL}$ of APTS reagent mixed in $50 \mathrm{~mL}$ of anhydrous toluene in a three-necked round bottom flask of $500 \mathrm{~mL}$. The mixture was refluxed at $100^{\circ} \mathrm{C}$ under stirring for 72 hours.

After the silanization reaction the solution was transferred to test tubes and centrifuged in a baby model FANEM centrifuge at $500 \mathrm{rpm}$ speed for 30 minutes in order to promote the sedimentation of the NPMs. Afterwards, the washing process was started using ethyl alcohol, the process repeated for 8 repetitions and then placed for FANEM Model 315 drying at $150^{\circ} \mathrm{C}$ for 12 hours. The signaling of the resulting sample was designated $\mathrm{NZ} @ \mathrm{SiO}_{2}$ and were submitted for characterizations.

For the functionalization process with chitosan the following reagents were used: chitosan - $\mathrm{Qs}-\left(\mathrm{C}_{12} \mathrm{H}_{24} \mathrm{~N}_{2} \mathrm{O}_{9}\right)$ 98\% - ALDRICH; Glacial acetic acid $\left(\mathrm{CH}_{3} \mathrm{COOH}\right)$ - SYNTH and sodium hydroxide $(\mathrm{NaOH})-\mathrm{SYNTH}$.

To functionalize of NPMs, $5 \mathrm{~g}$ of the silanized NPMs were added in $50 \mathrm{ml}$ of a solution of acetic acid $(1 \% \mathrm{v} / \mathrm{v})$ and $1 \mathrm{~g}$ of chitosan under mechanical stirring over a period of 2 hours. The mixture was poured into Petri dishes and dried in the oven at a temperature of about $60{ }^{\circ} \mathrm{C}$ for a period of 24 hours for complete evaporation of the solvent, resulting in a dry product. The product was allowed to immerse in basic solution for 2 hours.

After the neutralization reaction, the product was washed with distilled water (switching the water 8 times) and then dried at room temperature for 24 hours. Samples resulting from chitosan functionalization were designated as NZ@ $\mathrm{SiO}_{2}$ /chitosan and subsequently subjected to characterizations.

The determination of the phases present, crystallinity and crystallite size were determined from the diffraction data using an X-ray diffractometer SHIMADZU (model XRD 6000 , radiation $\mathrm{CuK}$ ). The crystallinity was determined from the ratio of the integrated area of the peak of crystalline phase and the amorphous area referring to the fraction. The average crystallite size was calculated from the line broadening of X-rays $\left(\mathrm{d}_{311}\right)$ by deconvolution of secondary diffraction line polycrystalline cerium (used as standard) using the equation of Scherrer.

FTIR spectra were obtained using a spectrometer FTIR/FT-NIR brand model 400 Perkin Elmer, between 4000 and $400 \mathrm{~cm}^{-1}$ at 4 resolution and 20 scans. The micrographs were obtained using a scanning electron microscope, Hitachi, model TM 1000. The thermogravimetric curves were obtained on a thermobalance, Shimadzu TGA-60, in nitrogen atmosphere with an alumina crucible, a flow of 50 $\mathrm{mL} / \mathrm{min}$ and heating rate $10^{\circ} \mathrm{C} / \mathrm{min}$, a temperature range varying ambient to $1000^{\circ} \mathrm{C}$.

The coercivity, remanent magnetization and saturation magnetization were obtained from the graph of hysteresis, observing the behavior of the curves near the origin of the cartesian plane. The hysteresis loss were determined by the area of $\mathrm{MxH}$. The cycles of magnetic hysteresis curve of the samples were obtained using an alternating gradient magnetometer (AGM).

\section{Results}

The Figure 1 illustrates the $\mathrm{x}$-ray diffractogram for the ferrite $\mathrm{Ni}_{0.5} \mathrm{Zn}_{0.5} \mathrm{Fe}_{2} \mathrm{O}_{4}$ obtained by combustion reaction (NZ) silanised with 3-aminopropyltrimethoxysilane silane agent (NZ@ $\mathrm{SiO}_{2}$ ) and functionalized with chitosan (NZ@ $\mathrm{SiO}_{2} /$ Chitosan). 


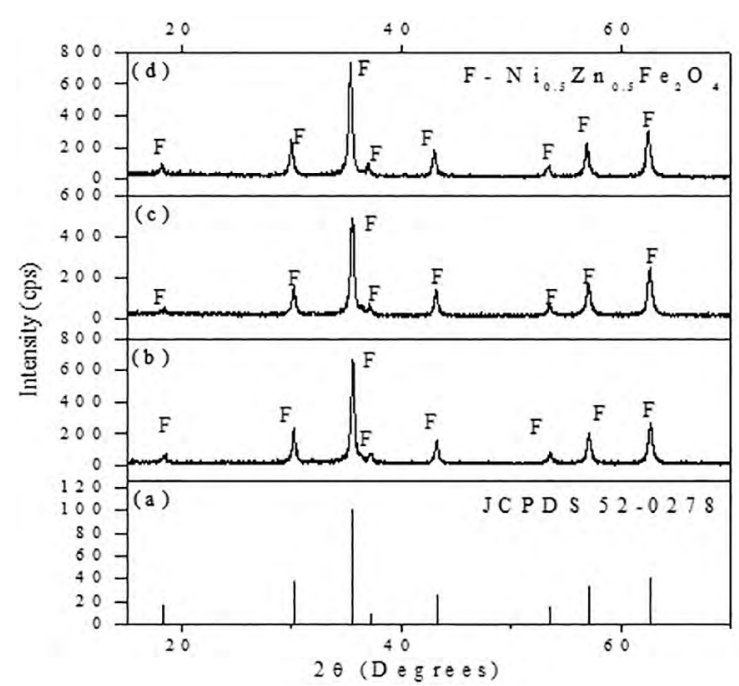

Figure 1. X-ray diffraction patterns for: (a) pattern JCPDS, (b) NZ, (c) $\mathrm{NZ} @ \mathrm{SiO}_{2}$ and (d) $\mathrm{NZ} @ \mathrm{SiO}_{2} /$ Chitosan.

For all samples it was observed the presence only of the main peaks characteristic of the inverse spinel structure as crystallographic forms JCPDF 52-0278. Comparing the X-ray spectra of the sample NZ samples $\mathrm{NZ} @ \mathrm{SiO}_{2}$ and $\mathrm{NZ} @ \mathrm{SiO}_{2} /$ Chitosan it is observed that they were similar, indicating that therefore, the addition of the silane agent followed by functionalization with the biopolymer chitosan did not cause structural change neither phase transition in the synthesized material, therefore, the structure of inverse spinel was preserved. There are also peaks with a considerable basal width in all reflections and they are well defined, indicating that they are crystalline materials with nanostructural characteristics.

Covaliu and his collaborators, $2013^{24}$ obtained nanostructured hybrid materials of $\mathrm{CoFe}_{2} \mathrm{O}_{4}$ coated with biopolymers polyvinylpyrrolidone (PVP) and polyethylene glycol (PEG) for biomedical applications and using the DRX technique concluded that nanostructured hybrid materials of $\mathrm{CoFe}_{2} \mathrm{O}_{4}$ after coating with PVP and PEG kept preserved the crystalline structure of ferrite. These results are in agreement with the results obtained by this work, ie, the biopolymer chitosan after added to the NiZn ferrite did not alter the structure of the ferrite.

Figure 2 presents the vibrational spectrum in the infrared region in the range of $4000-450 \mathrm{~cm}^{-1}$, samples of ferrite $\mathrm{Ni}_{0.5} \mathrm{Zn}_{0.5} \mathrm{Fe}_{2} \mathrm{O}_{4}$ obtained by combustion reaction (NZ), after signaling the agent silane 3- aminopropyltriethoxysilane (NZ@ $\mathrm{SiO}_{2}$ ) and functionalized chitosan (NZ@SiO /Chitosan).

According to the spectra of Figure 2, there are two absorption bands below $1000 \mathrm{~cm}^{-1}$, the bands $\mathrm{v}_{1}$ and $\mathrm{v}_{2}$, which are characteristic of the crystal lattice of $\mathrm{AB}_{2} \mathrm{O}_{4}$ spinel. It was observed that the absorption band $\mathrm{v}_{1}$ was localized approximately in the range of $815 \mathrm{~cm}^{-1}$ being attributed to the vibrations of the tetrahedral sites and $v_{2}$ band was located

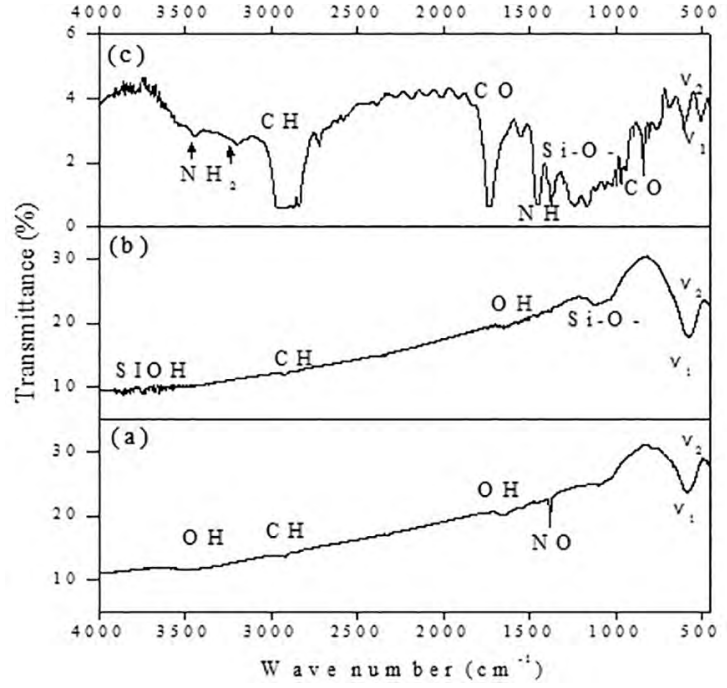

Figure 2. FTIR (a) NZ e (b) $\mathrm{NZ@} \mathrm{SiO}_{2}$ and (c) $\mathrm{NZ} @ \mathrm{SiO}_{2} / \mathrm{Chitosan}$.

approximately in the range of $490 \mathrm{~cm}^{-1}$ corresponding to the vibrations of the octahedral sites.

In Figure 2a, bands in the range of about $3660 \mathrm{~cm}^{-1}$ and $1500 \mathrm{~cm}^{-1}$ were observed, characteristics of O-H-O bonds, possibly of the presence of water in the sample, which can be obtained by atmospheric adsorption of atmospheric air that refers to Water adsorbed free and/or physically and also because of the $\mathrm{KBr}$ used for its preparation, which is hygroscopic and absorbs moisture easily.

Figure 2b shows stretching bands in the $2914 \mathrm{~cm}^{-1}$ region attributed to the aliphatic type $\mathrm{v}(\mathrm{CH}) \mathrm{sp}^{3}$. In 1635 $\mathrm{cm}^{-1}$ we observe an extensible band referring to the $\mathrm{CO}$, it can be attributed to the $\mathrm{CO}_{2}$ of the atmosphere. The multiple bands around $1124 \mathrm{~cm}^{-1}$ and $1033 \mathrm{~cm}^{-1}$ correspond to the asymmetric stretching $\mathrm{v}_{\text {ass }}$ Si-O, confirming the effectiveness of the silanization process. Also, bands below $1000 \mathrm{~cm}^{-1}$ are observed, which is characteristic of $\mathrm{Ni}_{0.5} \mathrm{Zn}_{0.5} \mathrm{Fe}_{2} \mathrm{O}_{4}$ spinel.

In Figure 2c, from 3450 to $3200 \mathrm{~cm}^{-1}$ weak absorptions attributed to $\mathrm{NH}$ bonds of primary amines are observed. The stretching bands in the region of $2919 \mathrm{~cm}^{-1}$ and 2773 $\mathrm{cm}^{-1}$ are caused by asymmetric and symmetrical stretching vibrations of $\mathrm{CH}$, respectively, of methyl radicals belonging to chitosan groups. The bands at $1740 \mathrm{~cm}^{-1}$ and $1554 \mathrm{~cm}^{-1}$ are related to the vibrations of $\mathrm{CO}$ and $\mathrm{NH}$, respectively.

In the range of $1456 \mathrm{~cm}^{-1}$ and $1364 \mathrm{~cm}^{-1}$ is an absorption which is attributable to symmetrical deformation of $\mathrm{CH}$. In $1254 \mathrm{~cm}^{-1}$ observes a band referring to stretching $\mathrm{Si}-\mathrm{CH}_{3}$ and in $1177 \mathrm{~cm}^{-1}$ a band assigned to the asymmetric stretching Si-O-Si. In 600 and $508 \mathrm{~cm}^{-1}$ bands were observed relating to the vibrations in the tetrahedral and octahedral sites in the spinel structure.

The Figure 3 illustrates the morphological characterization of ferrite $\mathrm{Ni}_{0.5} \mathrm{Zn}_{0.5} \mathrm{Fe}_{2} \mathrm{O}_{4}$ obtained by combustion reaction before (NZ), after signaling with silane agent 3-aminopropyltriethoxysilane $\left(\mathrm{NZ} @ \mathrm{SiO}_{2}\right)$ and functionalized chitosan (NZ@SiO $/$ Chitosan). 

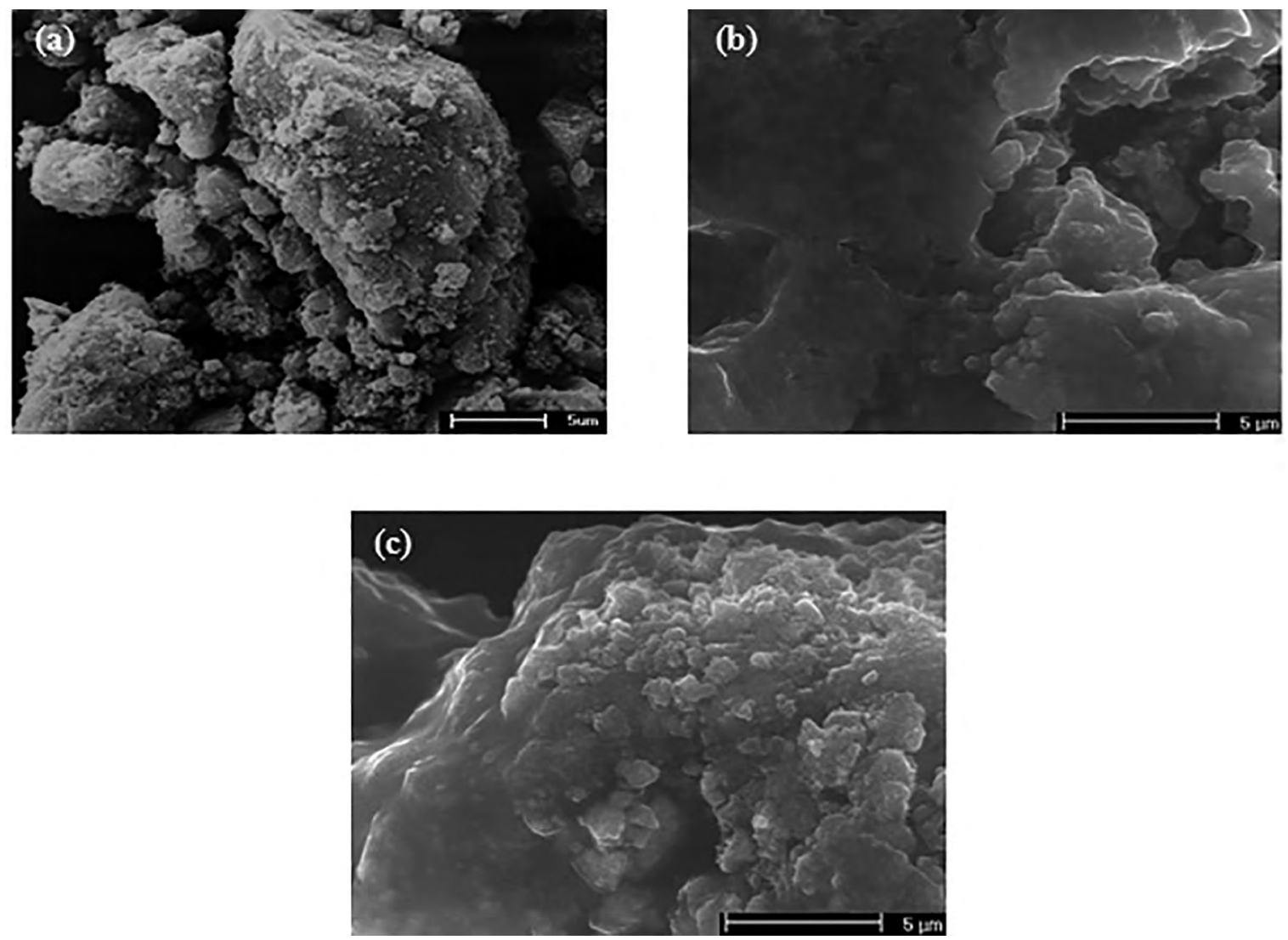

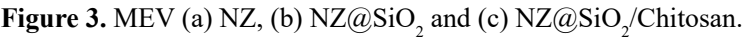

According to the micrograph presented in Figure 3a, were observed the formation of agglomerates larger than $5 \mu \mathrm{m}$, nonuniform and irregularly shaped were observed formation of agglomerates in the form of spongy blocks, frail, and presence of large pores which are released from the flue gas during synthesis.

According to the micrographs shown in Figure $3 b$ for the $\mathrm{NZ@SiO}$ ferrites, agglomerates with a stiffer aspect and low porosity are observed, possibly due to the covalent attachment of the silane to the surface of the NPMs, thus the presence of the silane agent promoted an effect sealant on the surface of the particle agglomerates. This same behavior was reported by Nadeem et al., $2014^{25}$ when they synthesized and studied $\mathrm{SiO}_{2}$ coated $\mathrm{NiFe}_{2} \mathrm{O}_{4}$ nanoparticles.

According to the micrographs shown in Figure $3 \mathrm{c}$ for ferrites after functionalization with chitosan it can be seen that agglomerated particles are not uniform in size and morphology, consisting of a film impregnated particles. It is observed so that the ferrites are presented as involved or encapsulated by chitosan. This same phenomenon was also observed by Sanjai et al. (2014) ${ }^{26}$ when they studied superparamagnetic iron oxide nanoparticles (SPIONPs) encapsulated with chitosan for use as a contrast agent for MRI, observed that for the morphology after addition of the chitosan a dispersibility of the SPIONPs, desirable for use in biomedical applications.
The Figure 4 illustrates the DTA and TGA curves for the ferrite $\mathrm{Ni}_{0.5} \mathrm{Zn}_{0.5} \mathrm{Fe}_{2} \mathrm{O}_{4}$ obtained by combustion reaction before (NZ), after signaling with silane agent 3-aminopropyltriethoxysilane $\left(\mathrm{NZ} @ \mathrm{SiO}_{2}\right)$ and functionalized chitosan (NZ@SiO $/$ chitosan).

With Figure 4a, it is noted that the NZ ferrites showed mass loss in three stages, in the range of $25-125^{\circ} \mathrm{C}$, of 0.581 mg equivalent to a percentage of mass loss $2.23 \%$, associated with adsorbed water and gases on the DTA curve represented by a maximum exothermic peak in $58.48^{\circ} \mathrm{C}$. The second mass loss occurred between $125-453^{\circ} \mathrm{C}$, it was $0.504 \mathrm{mg}$, which corresponds to a percentage loss $1.94 \%$. In $453-1000^{\circ} \mathrm{C}$ it is observed that the nanoparticles $\mathrm{Ni}_{0.5} \mathrm{Zn}_{0.5} \mathrm{Fe}_{2} \mathrm{O}_{4}$ they showed a mass loss $0.424 \mathrm{mg}$ equivalent to a percentage of mass loss $1.632 \%$, shown in DTA curve of a maximum endothermic peak in $548.35^{\circ} \mathrm{C}$.

With Figure 4b, it is noted that the $\mathrm{NZ} @ \mathrm{SiO}_{2}$ ferrite showed mass loss in three stages. The first weight loss occurred at a range of $25-227^{\circ} \mathrm{C}$, of $0.371 \mathrm{mg}$ equivalent to a percentage of mass loss $0.932 \%$, associated with adsorbed water and gases on the DTA curve represented by a maximum exothermic peak in $60.27^{\circ} \mathrm{C}$. The second mass loss corresponds to 0.915 mg equivalent to a percentage of mass loss $2.298 \%$, in the temperature range of 227 up until $532^{\circ} \mathrm{C}$, shown in DTA curve of a maximum endothermic peak in $319.8^{\circ} \mathrm{C}$. The third loss occurring in the range of $532-757^{\circ} \mathrm{C}$ of $0.154 \mathrm{mg}$ equivalent 

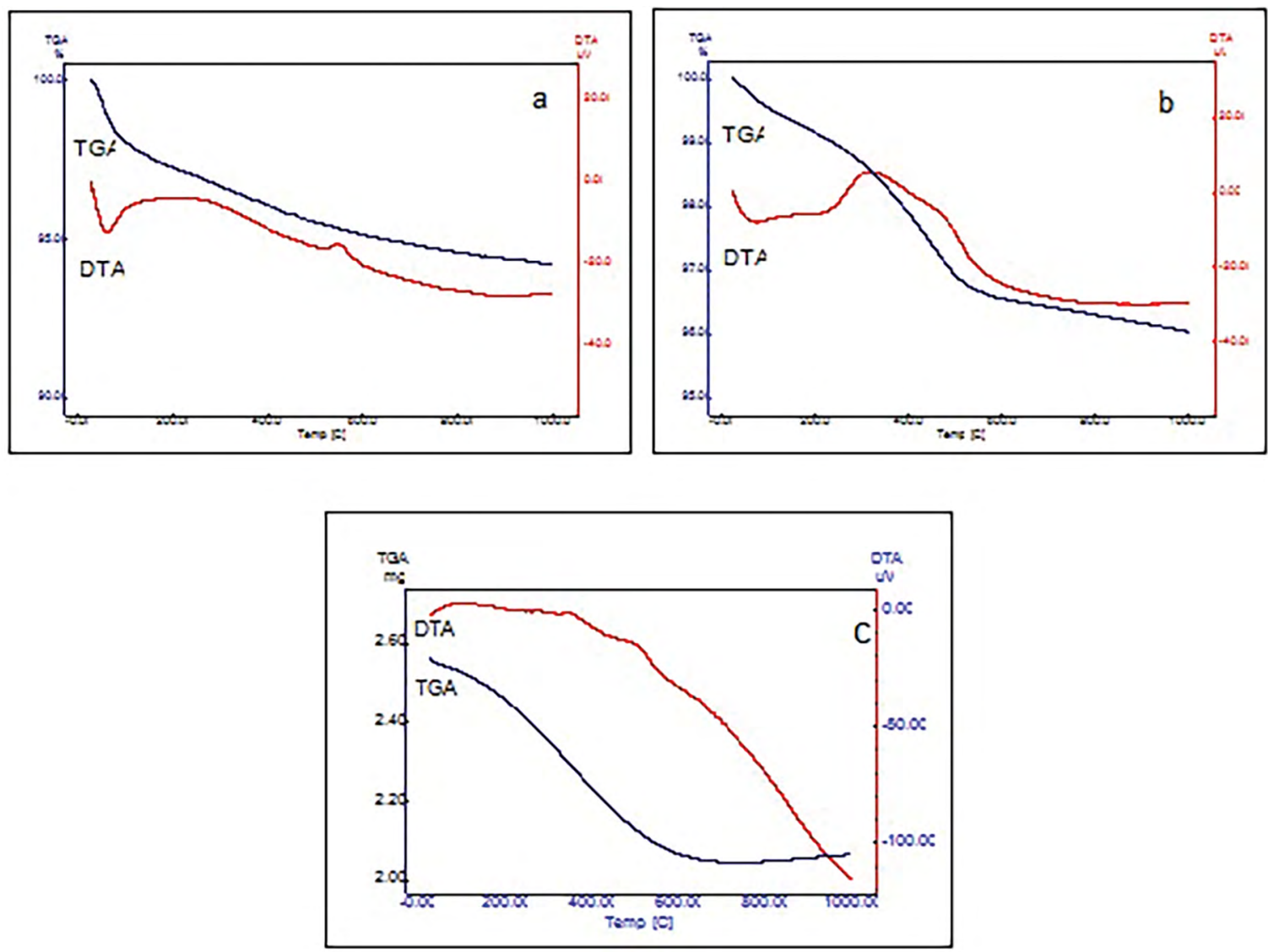

Figure 4. Thermogravimetric curves (a) NZ, (b) NZ@SiO $\mathrm{Sin}_{2}$ (c) $\mathrm{NZ} @ \mathrm{SiO}_{2} / \mathrm{Chitosan}$.

to a percentage of mass loss $0.387 \%$, shown in DTA curve of a maximum endothermic peak in $472^{\circ} \mathrm{C}$. Above $757^{\circ} \mathrm{C}$ reaches a step of thermal stability.

In Figure 4c, it is observed that the ferrites $\mathrm{NZ} @ \mathrm{SiO}_{2} /$ Chitosan showed weight loss in two stages. The first mass loss was $0.095 \mathrm{mg}$ equivalent to a percentage of mass loss $3.630 \%$, in the temperature range of $25-159^{\circ} \mathrm{C}$. The second weight loss occurred between $159-611^{\circ} \mathrm{C}$ it was $0.460 \mathrm{mg}$ corresponding to $17.577 \%$. Above $611^{\circ} \mathrm{C}$ it is observed that the nanoparticles $\mathrm{Ni}_{0.5} \mathrm{Zn}_{0.5} \mathrm{Fe}_{2} \mathrm{O}_{4}$ functionalized chitosan showed a level of stability. It is observed to a total mass loss of $21.2 \%$.

It is observed that the functionalized ferrite with chitosan (NZ@SiO 2 /Chitosan) presented higher mass loss when compared to the synthesized (NZ) and silanized with APTS (NZ@SiO $)$. Behavior similar to that which was also reported by Dodi et al., (2012) $)^{27}$ when studied nanocomposites magnetic particles with chitosan. This can be explained by the fact that chitosan is a polymer macromolecule that when subjected to high temperatures tend to suffer decomposition of its chain releasing subunits.

Figure 5 presents the dependence of the magnetization $\mathrm{M}$ as a function of applied magnetic field $\mathrm{H}$ for ferrite $\mathrm{Ni}_{0.5} \mathrm{Zn}_{0.5} \mathrm{Fe}_{2} \mathrm{O}_{4}$ obtained by combustion reaction before (NZ), after signaling with silane agent 3-aminopropyltriethoxysilane (NZ@ $\mathrm{SiO}_{2}$ ) and functionalized chitosan (NZ@SiO/Chitosan). It is observed that all samples have MxM narrow cycle is therefore characteristic of a soft magnetic material (which it is easy magnetization and demagnetization).

Upon the hysteresis curves in Figure 5, it can be seen that after silanization the saturation magnetization and the coercivity, remained almost constant, indicating that the silane content used did not affect the magnetic behavior in the ferrite. After functionalization with chitosan it was observed that the saturation magnetization was decreased by $37.5 \%$ and coercivity remains constant.

Wang et al., $(2011)^{28}$, prepared nanoparticles of $\mathrm{CoFe}_{2} \mathrm{O}_{4}$ monodisperse in $\mathrm{SiO}_{2}$ and then functionalized with amino for the purpose of immobilizing enzymes and observed that the saturation magnetization has decreased after the NPMs be functionalized and attributed this to the effect of the coating layer of amorphous silica on the NPMs in agreement with the results obtained in this work.

Tang et al., (2012) ${ }^{29}$, when they studied the composite $\mathrm{Co}_{0.8} \mathrm{Ni}_{0.2} \mathrm{Fe}_{2} \mathrm{O}_{4} / \mathrm{PVP}$ using the silane coupling agent methacrylate, 3- (trimethoxysilyl) observed behavior similar to that reported for this work, because the saturation magnetization observed with the composite $\mathrm{Co}_{0.8} \mathrm{Ni}_{0.2} \mathrm{Fe}_{2} \mathrm{O}_{4} / \mathrm{PVP}$ it was lower as 

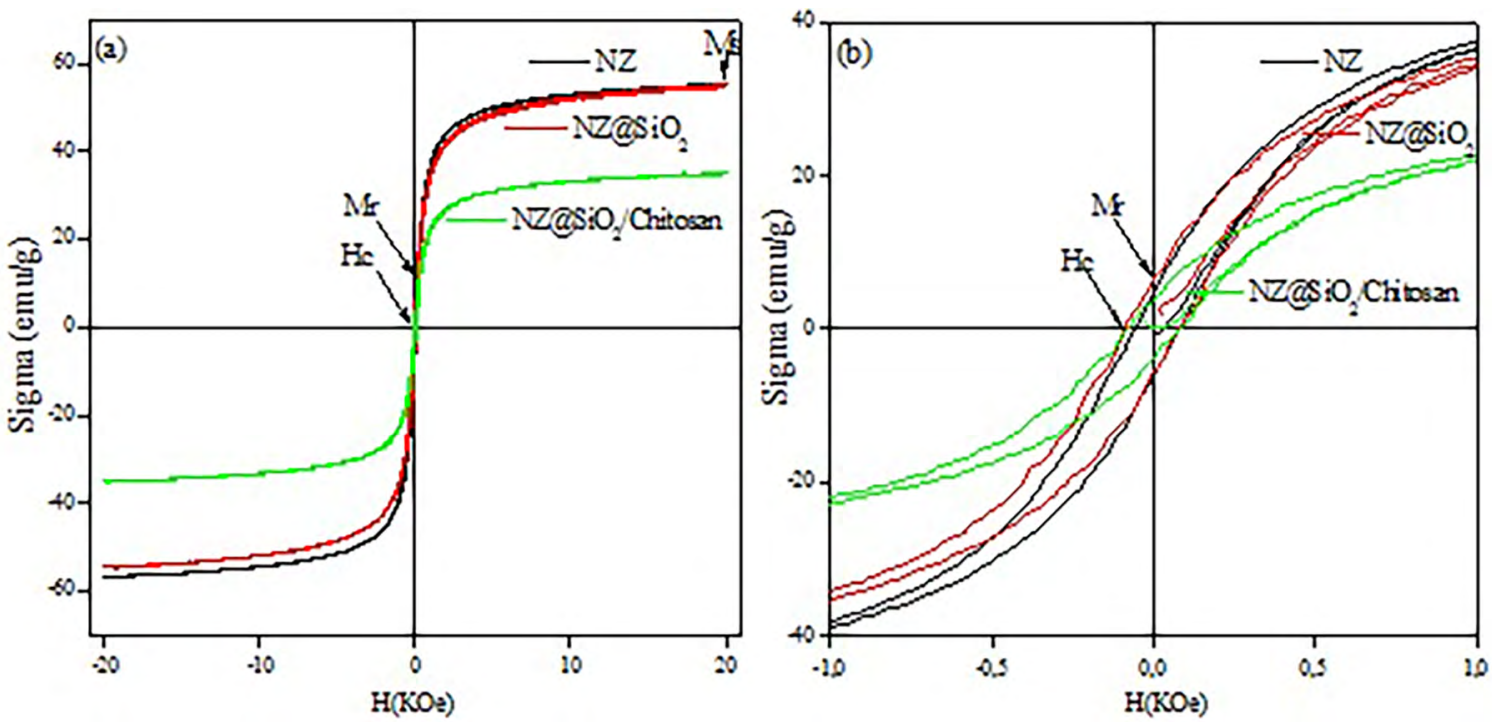

Figure 5. Hysteresis curves for (a) NZ, NZ@SiO and $\mathrm{NZ@SiO} /$ Chitosan and (b) expansion NZ, $\mathrm{NZ@SiO} \mathrm{S}_{2}$ and $\mathrm{NZ} @ \mathrm{SiO}_{2} / \mathrm{Chitosan}$.

compared with the NPMs of $\mathrm{Co}_{0.8} \mathrm{Ni}_{0.2} \mathrm{Fe}_{2} \mathrm{O}_{4}$. This reduction in saturation magnetization is attributed to the presence of PVP which is non-magnetic, which influences the uniformity and magnitude of magnetization of the magnetic moment quench surface.

Table 1 presents the magnetic parameters lies (saturation magnetization, remnant magnetization, coercive field and hysteresis losses) obtained by means of hysteresis curves of these materials for ferrites NZ, NZ@SiO e NZ@, $\mathrm{SiO}_{2} /$ Chitosan.

Table 1. Hysteresis Parameters to NZ, NZ@SiO 2 and NZ@ $\mathrm{SiO}_{2} /$ Chitosan.

\begin{tabular}{|c|c|c|c|c|}
\hline Sample & $\begin{array}{c}\mathrm{Ms} \\
(\mathrm{meu} / \mathrm{g})\end{array}$ & $\begin{array}{c}\mathrm{Mr} \\
(\mathrm{meu} / \mathrm{g})\end{array}$ & $\begin{array}{c}\mathrm{Hc} \\
(\mathrm{kOe})\end{array}$ & $\mathrm{Mr} / \mathrm{Ms}$ \\
\hline $\mathrm{NZ}$ & 56 & 5.0 & 74 & 0.089 \\
\hline $\mathrm{NZ} @ \mathrm{SiO}_{2}$ & 55 & 6.0 & 86 & 0.109 \\
\hline $\mathrm{NZ} @ \mathrm{SiO}_{2} /$ Chitosan & 35 & 4.0 & 80 & 0.114 \\
\hline
\end{tabular}

With the data in Table 1, it was found ferrite $\mathrm{NZ} @ \mathrm{SiO}_{2}$ after signaling resulted in a saturation magnetization $1.81 \%$ lower when compared to the ferrite sintered NZ. It is observed that functionalization with chitosan ferrite causes a reduction in saturation magnetization $37.5 \%$, when compared to the as sintered ferrite.

From these results, it is noted that the materials indicate that after the silanization and functionalization with chitosan biopolymer, the magnetic characteristics remain in the material, ie, the sample continued to be attracted by the magnetic field. For the results of remnant magnetization (Mr) and coercive field ( $\mathrm{Hc})$, it was observed that after the withdrawal of the external magnetic field the ferrites in the study presented values that oscillate of remnant magnetization and coercive field, thus proving that they are not superparamagnetic. For the nanoparticles to be superparamagnetic, it is necessary that they do not retain any magnetism after removal of the external magnetic field, present strong values of saturation magnetization, zero coercive field and absence of hysteresis ${ }^{30,31}$.

\section{Conclusions}

According to the objective of the present work, it was possible to obtain the hybrid $\mathrm{Ni}_{0.5} \mathrm{Zn}_{0.5} \mathrm{Fe}_{2} \mathrm{O}_{4} @ \mathrm{SiO}_{2} /$ Chitosan successfully tested for the presence of silanol and chitosan groups in the ferrite structure. The introduction of silane and biopolymer chitosan did not interfere with the ferrite structure. The presence of silane and chitosan reduced the magnetization, but maintained the ferrimagnetic characteristic presented by the ferrite. The hybrid $\mathrm{Ni}_{0.5} \mathrm{Zn}_{0.5} \mathrm{Fe}_{2} \mathrm{O}_{4} @ \mathrm{SiO}_{2} /$ Chitosan has been successfully obtained by being promising for use in biotechnology applications such as a magnetic biosensor.

\section{Acknowledgments}

The authors acknowledge the financial support of CNPq, CAPES, Inct-INAMI.

\section{References}

1. Spirk S, Findenig G, Doliska A, Reichel VE, Swanson NL, Kargl R, et al. Chitosan-silane sol-gel hybrid thin films with controllable layer thickness and morphology. Carbohydrate Polymers. 2013;93(1):285-290.

2. Gamys CG, Beyou E, Bourgeat-Lami E. Micellar behavior of well-defined polystyrene-based block copolymers with triethoxysilyl reactive groups and their hydrolysis-condensation. Journal of Polymer Science Part A: Polymer Chemistry. 2010;48(4):784-793. 
3. Müllner M, Schallon A, Walther A, Freitag R, Müller AHE. Clickable, Biocompatible, and Fluorescent Hybrid Nanoparticles for Intracellular Delivery and Optical Imaging. Biomacromolecules. 2010;11(2):390-396.

4. Jayakumar R, Chennazhi KP, Muzzarelli RAA, Tamura H, Nair SV, Selvamurugan N. Chitosan conjugated DNA nanoparticles in gene therapy. Carbohydrate Polymers. 2010;79(1):1-8.

5. Lei L, Cao Z, Xie Q, Fu Y, Tan Y, Ma M, et al. One-pot electrodeposition of 3-aminopropyltriethoxysilane-chitosan hybrid gel film to immobilize glucose oxidase for biosensing. Sensors and Actuators B: Chemical. 2011;157(1):282-289.

6. Yang F, Jin C, Subedi S, Lee CL, Wang Q, Jiang Y, et al. Emerging inorganic nanomaterials for pancreatic cancer diagnosis and treatment. Cancer Treatment Reviews. 2012;38(6):566-579.

7. Durdureanu-Angheluta A, Dascalu A, Fifere A, Coroaba A, Pricop L, Chiriac H, et al. Progress in the synthesis and characterization of magnetite nanoparticles with amino groups on the surface. Journal of Magnetism and Magnetic Materials. 2012;324(9):1679-1689.

8. Ozyilmaz E, Sayin S, Arslan M, Yilmaz M. Improving catalytic hydrolysis reaction efficiency of sol-gel-encapsulated Candida rugosa lipase with magnetic $\beta$-cyclodextrin nanoparticles. Colloids and Surfaces B: Biointerfaces. 2014;113:182-189.

9. Qiang L, Li Z, Zhao T, Zhong S, Wang H, Cui X. Atomicscale interactions of the interface between chitosan and $\mathrm{Fe}_{3} \mathrm{O}_{4}$. Colloids and Surfaces A: Physicochemical and Engineering Aspects. 2013;419:125-132.

10. Wang X, Wu P, Lv Y, Xiandeng H. Ultrasensitive fluorescence detection of glutaraldehyde in water samples with bovine serum albumin-Au nanoclusters. Microchemical Journal. 2011;99(2):327-331.

11. Shundo C, Zhang H, Nakanishi T, Osaka T. Cytotoxicity evaluation of magnetite $\left(\mathrm{Fe}_{3} \mathrm{O}_{4}\right)$ nanoparticles in mouse embryonic stem cells. Colloids and Surfaces B: Biointerfaces. 2012;97:221-225.

12. Sobczak-Kupiec A, Venkatesan J, AlAnezi AA, Walczyk D, Farooqi A, Malina D, et al. Magnetic nanomaterials and sensors for biological detection. Nanomedicine: Nanotechnology, Biology and Medicine. 2016;12(8):2459-2473.

13. Cornell RM, Schwertmann U. The Iron Oxides: Structure, Properties, Reactions, Occurrences and Uses. Weinheim: Wiley-VCH; 2006.

14. Laurent S, Mahmoudi M. Superparamagnetic iron oxide nanoparticles: promises for diagnosis and treatment of cancer. International Journal of Molecular Epidemiology and Genetics. 2011;2(4):367-390.

15. Jiang $\mathrm{C}$, Liu $\mathrm{R}$, Shen $\mathrm{X}$, Zhu L, Song F. $\mathrm{Ni}_{0.5} \mathrm{Zn}_{0.5} \mathrm{Fe}_{2} \mathrm{O}_{4}$ nanoparticles and their magnetic properties and adsorption of bovine serum albumin. Powder Technology. 2011;211(1):90-94.

16. Sharifi I, Shokrollahi H, Amiri S. Ferrite-based magnetic nanofluids used in hyperthermia applications. Journal of Magnetism and Magnetic Materials. 2012;324(6):903-915.

17. Nowick AM, Kowalczyk A, Donten M, Krysinski P, Stojek Z. Influence of a Magnetic Nanoparticle As a Drug Carrier on the
Activity of Anticancer Drugs: Interactions of Double Stranded DNA and Doxorubicin Modified with a Carrier. Analytical Chemistry. 2009;81(17):7474-7483.

18. Sunkara BK, Misra RDK. Enhanced antibactericidal function of $\mathrm{W}^{4+}$-doped titania-coated nickel ferrite composite nanoparticles: A biomaterial system. Acta Biomaterialia. 2008;4(2):273-283.

19. Costa CN, Costa MAS, Maria LCS, Silva MR, Souza Jr FG, Michel R. Síntese e caracterização de copolímeros à base de metacrilato de metila e divinilbenzeno com propriedades magnéticas. Polímeros. 2012;22(3):260-266.

20. Yardimci FS, Senel M, Baykal A. Amperometric hydrogen peroxide biosensor based on cobalt ferrite-chitosan nanocomposite. Materials Science and Engineering: C. 2012;32(2):269-275.

21. Fernandes LL, Resende CX, Tavares DS, Soares GA, Castro LO, Granjeiro JM. Cytocompatibility of chitosan and collagen-chitosan scaffolds for tissue engineering. Polimeros. 2011;21(1):1-6.

22. Jain SR, Adiga KC, Pai Verneker VR. A new approach to thermochemical calculations of condensed fuel-oxidizer mixtures. Combustion and Flame. 1981;40:71-79.

23. Costa ACFM, Kiminami RHGA, inventors. Dispositivo para produção de nanomateriais cerâmicos em larga escala por reação de combustão e processo contínuo de produção dos nanomateriais. Patent deposit. BR 102012 002181-3. 2012 Jan 25 .

24. Covaliu CI, Jitaru I, Paraschiv G, Vasile E, Biris SS, Diamandescu $\mathrm{L}$, et al. Core-shell hybrid nanomaterials based on $\mathrm{CoFe}_{2} \mathrm{O}_{4}$ particles coated with PVP or PEG biopolymers for applications in biomedicine. Powder Technology. 2013;237:415-426.

25. Nadeem K, Krenn H, Sarwar W, Mumtaz M. Comparison of surface effects in $\mathrm{SiO}_{2}$ coated and uncoated nickel ferrite nanoparticles. Applied Surface Science. 2014;288:677-681.

26. Sanjai C, Kothan S, Gonil P, Saesoo S, Sajomsang W. Chitosantriphosphate nanoparticles for encapsulation of super-paramagnetic iron oxide as an MRI contrast agent. Carbohydrate Polymers. 2014; 104:231-237.

27. Dodi G, Hritcu D, Lisa G, Popa MI. Core-shell magnetic chitosan particles functionalized by grafting: Synthesis and characterization. Chemical Engineering Journal. 2012;203:130141.

28. Wang H, Huang J, Wang C, Li D, Ding L, Han Y. Immobilization of glucose oxidase using $\mathrm{CoFe}_{2} \mathrm{O}_{4} / \mathrm{SiO}_{2}$ nanoparticles as carrier. Applied Surface Science. 2011;257(13):5739-5745.

29. Tang Y, Wang $\mathrm{X}$, Zhang Q, Li Y, Wang H. Fabrication and characterization of high solid content $\mathrm{Co}_{0.8} \mathrm{Ni}_{0.2} \mathrm{Fe}_{2} \mathrm{O}_{4} / \mathrm{PVP}$ composite nanofibers by direct-dispersed electrospinning. Synthetic Metals. 2012;162(3-4):309-313.

30. Mathew DS, Juang RS. An overview of the structure and magnetism of spinel ferrite nanoparticles and their synthesis in microemulsions. Chemical Engineering Journal. 2007;129(13):51-65.

31. Karimi Z, Karimi L, Shokrollahi H. Nano-magnetic particles used in biomedicine: Core and coating materials. Materials Science and Engineering: C. 2013;33(5):2465-2475. 